\title{
Progress and Prospect of Research on University-Industry Cooperation: From the Perspective of Researchers
}

\author{
Junwen He \\ School of Management, Jinan University, Guangzhou, China \\ Email: jnuhejunwen@126.com
}

How to cite this paper: He, J. W. (2020). Progress and Prospect of Research on University-Industry Cooperation: From the Perspective of Researchers. American Journal of Industrial and Business Management, 10, 920-934.

https://doi.org/10.4236/ajibm.2020.105062

Received: April 10, 2020

Accepted: May 10, 2020

Published: May 13, 2020

Copyright $\odot 2020$ by author(s) and Scientific Research Publishing Inc. This work is licensed under the Creative Commons Attribution International License (CC BY 4.0).

http://creativecommons.org/licenses/by/4.0/

\begin{abstract}
By reviewing the research literature on the interaction of production, study and research, this paper discusses the current research situation of the interaction of production, study and research, especially the research of the research center of the university researchers. Pass summarizing the methods, achievements and shortcomings of the current research, it is pointed out that there are few researches related to the interactive form of human mobility, and that the impact of university-industry cooperation on the academic and innovative performance of researchers has different conclusions in academia. Finally, the direction of follow-up research is put forward.
\end{abstract}

\section{Keywords}

University-Industry Interaction, Interactive Form, Academic Performance, Patent Output, Impact Factors

\section{Introduction}

University-industry cooperation is the main way to transfer scientific and technological achievements, and it is an important part of the national innovation system. The Chinese government has always attached great importance to university-industry cooperation, especially since implemented the national innovation-driven development strategy, the deep integration of production and research has been mentioned to a new height. The government, universities and enterprises all hope to build the institutional mechanism of the deep integration of production and research, promote the transformation of scientific and technological achievements, and realize the development of innovation-driven. With the help of practice, the academic community actively responds to study the new 
problems and challenges facing the field in-depth, however, the premise of the in-depth study is to make a deeper understanding and summary of the research already in the field. University researchers are the bearers of the cooperative projects of production and research. Meanwhile, how to promote the participation of university researchers in the cooperative project, and how to balance the transformation of academic research and innovation achievements of scientific research personnel, in that due to fully stimulate the innovation ability of university researchers, is the focus of the government's industrial-academic policy. In this context, it is greatly practical and theoretical significance to summarize and evaluate the university-industry cooperation research of domestic and foreign, and to analyze the literature with university researchers as the research object for the follow-up research.

\section{Document Descriptive Analysis}

\subsection{Research Methodology}

In order to fully understand the current research status and development dynamics in the field of internationalization of research and development, this study uses a systematic literature review to comb the relevant research literature at home and abroad. The systematic literature review method originated from the medical discipline, the main purpose is to use systematic, transparent and repeatable process to synthesize the existing literature, in order to reduce the potential deviation to improve the quality of literature review. In recent years, systematic literature review methods have been increasingly applied to different research areas of management, such as the university-industry cooperation. The systematic literature review method used in this study mainly includes the following 6 steps: 1) defining the research problem; 2) defining the scope of the literature; 3) retrieving the literature database; 4) screening the relevant literature; 5) comprehensive analysis of the literature; and 6) presenting the results of the literature review.

First of all, starting from the core issues mentioned in the previous article, the main research objective of this study is 1-Explore the influence factors of scientific research personnel' participation in the university-industry cooperation. 2-The impact of the university-industry cooperation on the academic and innovative performance of scientific researchers. Based on this, this study defines the following document inclusion/exclusion rules to determine the scope of the literature to be retrieved: 1) Contains articles related to the university-industry cooperation, collect literature from the individual level of scientific researchers, and exclude the research samples from articles for enterprises, universities and scientific research institutions. 2) Contains literature in important international and Chinese academic journals. 3) In order to prevent omission, generally reading of all literature in academic journals published in the context of the issue for nearly 10 years.

Next, the study selected the SCI/SSCI Source Journal in Web of Science as the 
source of literature retrieval in international journals, and the CSSCI Source Journal in CNKI as the source of Chinese literature retrieval. These two databases cover most of the major international and Chinese academic journals, providing a representative literature sample for this study. Based on the scope of the literature that has been initially defined, the study uses the corresponding Chinese and English keywords to search the two databases, and further uses the inclusion/exclusion rules to screen the retrieved documents in order to construct the final collection of literature samples for analysis.

\subsection{Data Sources}

Search 3628 articles on the theme of school-enterprise cooperation in web of science, obtain more than 2000 articles through the screening of the field of research, and then select the literature to carry out the research on the university-industry cooperation at the individual level by reading the title, keywords and abstracts, and remove the research at the enterprise level, focusing on the researchers' cooperation in university-industry cooperation. In order to avoid omission, the two journals with the largest number of papers on the topic, Research Policy, Journal of Technology Transfer, published in 2000-2019, read the relevant literature one by one, and through the above steps, 83 related documents published from 2000 to 2019 included 3 reviews of literature, and read these documents. Using a similar method, the study used the keyword "university-industry cooperation" to retrieve CSSCI source journals in CNKI data and obtained 2535 records. Similarly, by reading topics, keywords and abstracts on a case-by-case basis, applying inclusion/exclusion rules screening, 24 Chinese literatures are entered into the analysis sample set. The study also used "Enterprise Science and Technology Commissioner" as the keyword to search the CSSCI source journal in CNKI data, and found a total of 41 articles. Excluding the literature of the research sample as the agricultural science and technology commissioner, a total of 13 documents were obtained with the enterprise science and technology commissioner as the research subject. Finally, we obtained 107 literatures concerned about the personal level in the field of production, and 13 literatures research on the policy of enterprise science and technology commissioners, and incorporated these documents into the descriptive analysis.

\subsection{Analysis of Literature Description}

Judging from the time distribution of the publication of relevant literature from university-industry cooperation, overall, shown in Figure 1, the literature in this field showed an upward trend in volatility between 2000 and 2019. In terms of time, international scholars' research on individuals originated earlier (1987) and domestic scholars' research on individuals was relatively late (2011). From the quantitative point of view, the international research on the individual level is more abundant, the number of relevant articles published each year is higher than at home, but in recent years, the domestic gradually pay attention to the re- 
levant issues of research, in 2018 the number of domestic articles published more than the international.

From the distribution of journals published in the relevant literature obtained by Web of Science (Table 1), these articles are published primarily in the Journal of Innovation Research such as Research Policy, Journal of Technology Transfer, Technovation and so on. The top 3 journals in the number of papers published accounted for $70 \%$ of the total, with a high degree of concentration. The search of CNKI relevant literature of UIC published journals (Table 2), these articles are mainly published in innovative research journals such as scientific and technological progress and countermeasures, science and technology management, science and technology management research and so on. The top 5 journals in the number of papers published accounted for $54 \%$ of the total, with a high degree of concentration.

From the data sources of international papers, such as Table 3, the literature

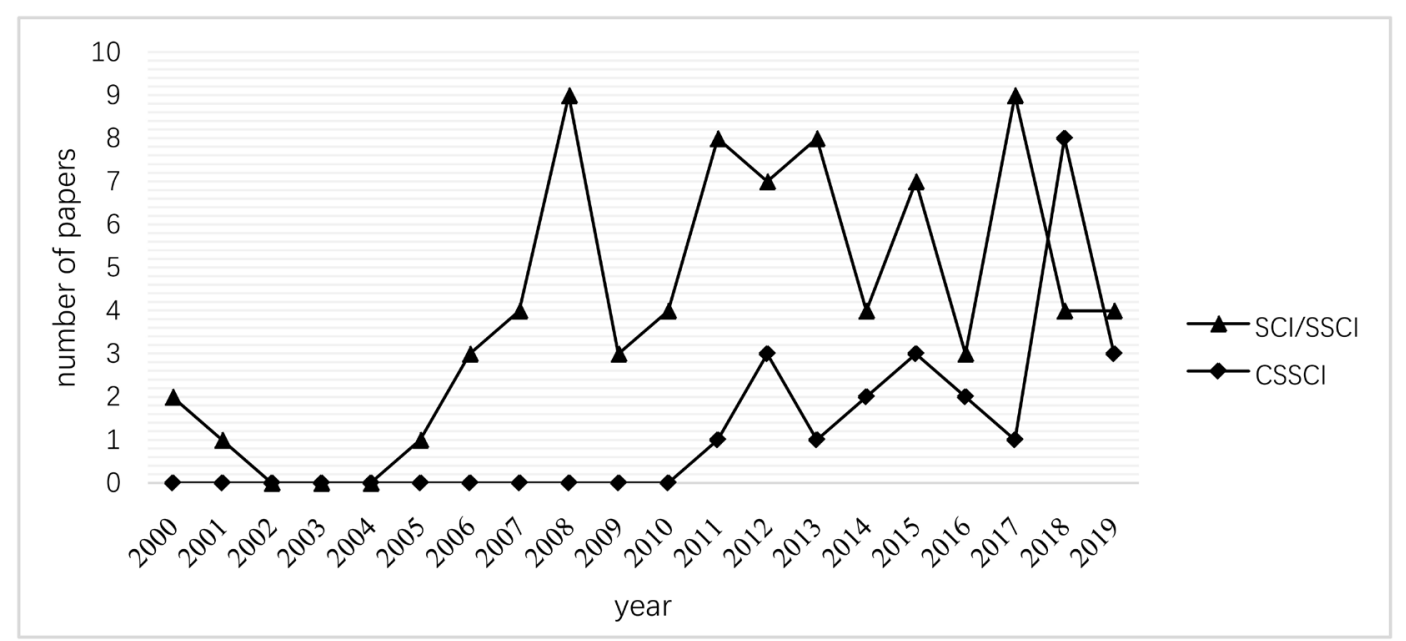

Figure 1. Annual distribution of literature obtained from Web of Science and CNKI (2000-2019).

Table 1. Journals distribution of literature obtained from Web of Science.

\begin{tabular}{cc}
\hline Journals & Number of literatures \\
Research Policy & 28 \\
Journal of Technology Transfer & 25 \\
Technovation & 3 \\
Cambridge Journal of Economics & 2 \\
Economics of Innovation and New Technology & 2 \\
Journal of Product Innovation Management & 2 \\
International Journal of Industrial Organization & 2 \\
Organization Science & 2 \\
Regional Studies & 2 \\
Others & 12 \\
Total & 80 \\
\hline
\end{tabular}


Table 2. Journals distribution of literature obtained from CNKI.

\begin{tabular}{cc}
\hline Journals & Number of literatures \\
\hline Science \& Technology Progress and Policy & 4 \\
Science of Science and Management of S \& T & 3 \\
Soft Science & 2 \\
Science and Technology Management Research & 2 \\
Chinese Journal of Management & 2 \\
Others & 11 \\
Total & 24 \\
\hline
\end{tabular}

Table 3. Data source of article of web of science.

\begin{tabular}{ccc}
\hline Data source & Number of literatures & Percentage \\
\hline UK & 31 & $38.75 \%$ \\
The United States & 11 & $13.75 \%$ \\
Other European countries & 29 & $36.25 \%$ \\
Other countries & 8 & $10 \%$ \\
Asian countries & 1 & $1.25 \%$ \\
Total & 80 & $100 \%$ \\
\hline
\end{tabular}

more examined the UK, The United States and other European countries (accounting for $88.7 \%$ of the total number of papers), the international has not yet paid attention to the interaction of Chinese researchers in industry and research. Different countries have different industrial, academic and research policies, different technical environment, and their research results will be different. Therefore, the research on this topic in the Chinese situation is currently in a blank international situation, and the study of UIC from the individual-level of scientific researchers in the Chinese situation is an urgent topic in the world, which is of great theoretical significance.

Through the careful reading of these 107 (3 reviews) of the literature, it is found that the research generally explores the former and consequences of scientific researchers' participation in the interaction of industry and research: First, to make the influence factors to participate in UIC, The second is the impact on researchers involved in the UIC. This paper distinguishes the literature into these two topics, although $3(0.03 \%)$ Chinese CSSCI explores other topics. After that, these research topics, literature data types, research methods are descriptive analysis.

First, from the number of documents such as Table 4, there are international 58 articles (72.5\%) explore the factors of UIC, 22 articles (27.5\%) explore the impacts of UIC, all through empirical analysis of the method of analysis. Among them, 58 articles $(72.5 \%)$ based on questionnaire data, 21 articles based on second-hand data (26\%), and 1 based on case studies. It shows that the existing 
international papers are generally based on the method of empirical analysis, based on the questionnaire collection of personal data of researchers, and the research topic spars the influence factors of UIC. While the relevant situation of domestic CSSCI papers such as Table 5, domestic papers to explore the UIC of 24 articles, there are 7 articles (29.2\%) explore the factors of UIC, 17 articles (70.8\%) explore the impacts of UIC, all through empirical analysis of the method of analysis. Among them, 15 articles based on questionnaire data (71\%), 3 articles based on second-hand data (12.5\%), 6 articles without data (25\%). It shows that the existing domestic papers are generally based on the method of empirical analysis, based on the questionnaire collection of personal data of researchers, and different from international papers, the topic of domestic research focuses on the impact of the interaction between industry, science and research.

Second, from the perspective of time trend, as shown in Figure 2 and Figure 3 , the research topics are divided into two categories, and the time development trend is observed. From the perspective of international papers, research has always been focused on the influencing factors of UIC, until 2011, the issues of UIC have gradually increased. In 2011, Chinese researchers just began to pay attention to the research on the individual level of UIC, so the domestic papers focus on the research on issues about the impact of UIC.

Table 4. SCI/SSCI article research topic distribution and data type distribution.

\begin{tabular}{cccc}
\hline $\begin{array}{c}\text { Research } \\
\text { topics }\end{array}$ & Data type & Method & $\begin{array}{c}\text { Number of } \\
\text { literatures }\end{array}$ \\
\hline Factors & questionnaire data & Empirical analysis & 43 \\
& Secondary data & Empirical analysis & 11 \\
& questionnaire data \& Secondary data & Empirical analysis & 3 \\
Impacts & Case & Empirical analysis & 1 \\
& Suestionnaire data & Empirical analysis & 9 \\
& Secondary data & Empirical analysis & 10 \\
& questionnaire data \& Secondary data & Empirical analysis & 3 \\
\hline
\end{tabular}

Table 5. CSSCI article research topic distribution and data type distribution.

\begin{tabular}{cccc}
\hline Research topics & Data type & Method & Number of literatures \\
\hline Factors & questionnaire data & Empirical analysis & 4 \\
& Secondary data & Empirical analysis & 0 \\
& n/a & Theoretical analysis & 3 \\
Impacts & questionnaire data & Empirical analysis & 11 \\
& Secondary data & Empirical analysis & 3 \\
Others & n/a & Theoretical analysis & 3 \\
Total & & & 24 \\
\hline
\end{tabular}




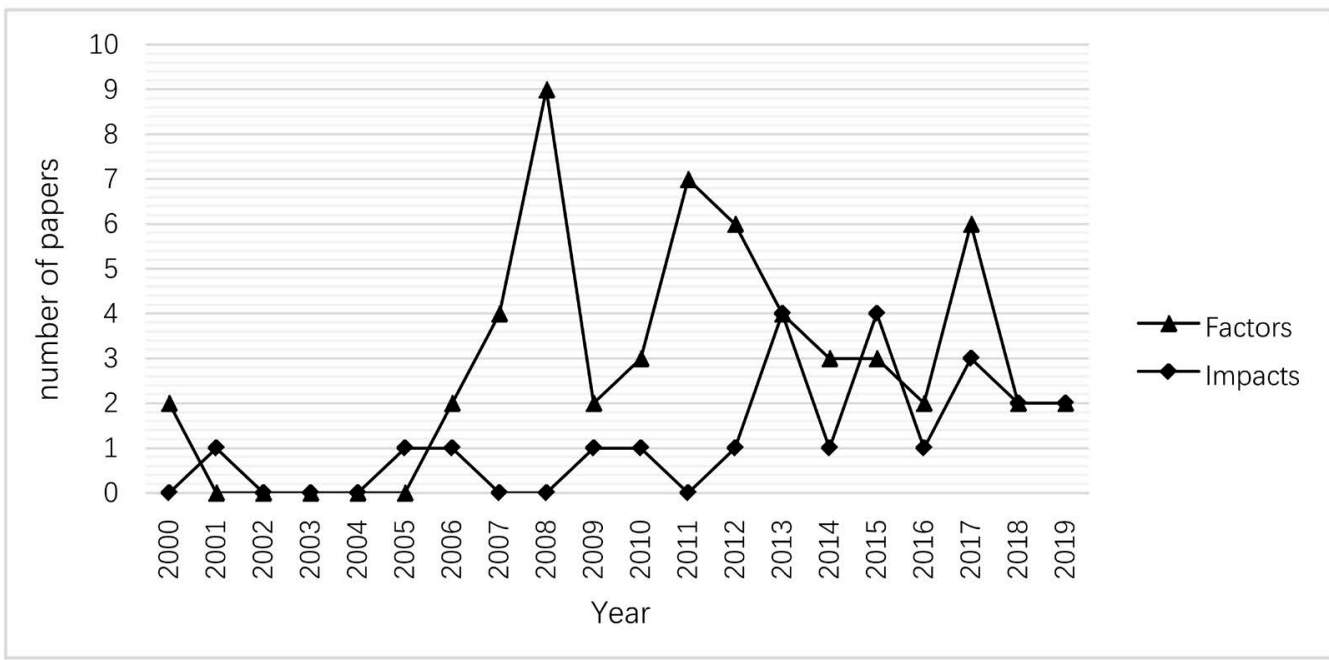

Figure 2. Annual distribution of related thesis topics in the field of UIC obtained by Web of Science (2000-2019).

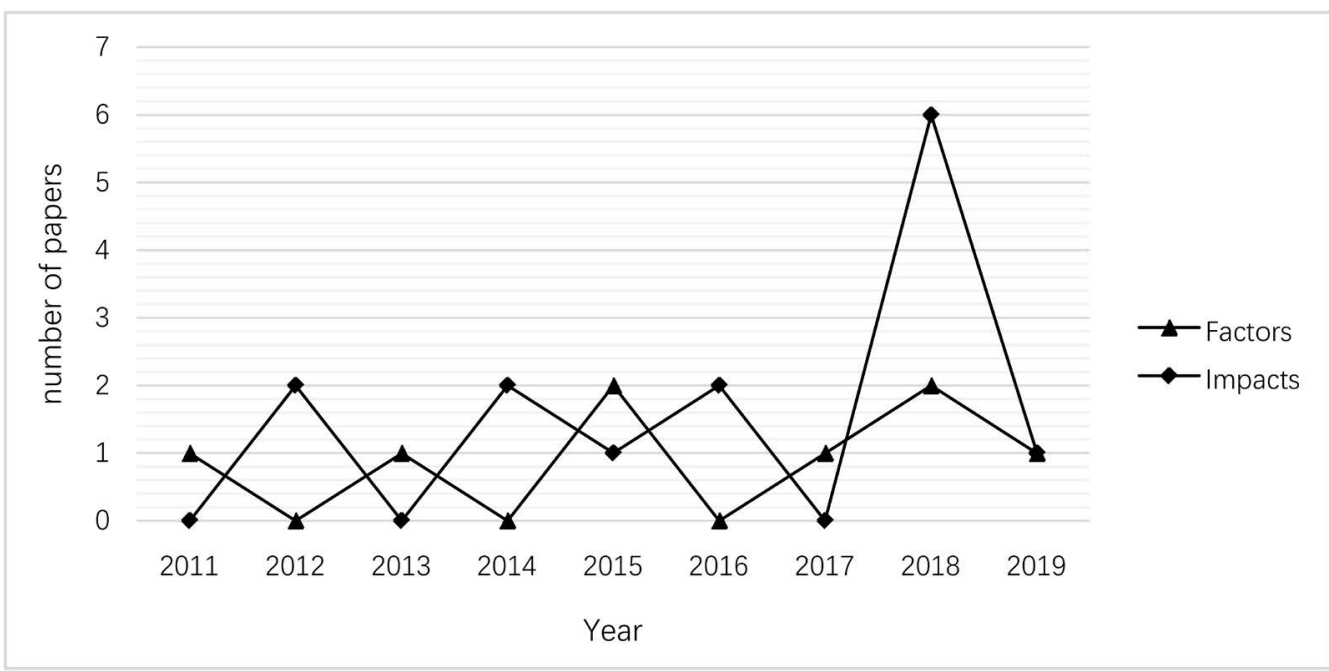

Figure 3. Annual distribution of related thesis topics in the field of UIC obtained by CNKI (2011-2019).

To sum up, the descriptive analysis of all the literature on the industry university research at the individual level shows that: in recent years, the domestic and foreign academic circles have begun to pay attention to the research on the impact of the participation of scientific researchers in the UIC, and the empirical research method is the main research method at home and abroad. Due to the difficulty of obtaining personal data from the second-hand data, most of the researches on related topics are based on the personal data obtained by questionnaire, but the personal research is greatly influenced by subjective factors, and does not have the objectivity of the second-hand data.

Finally, through in-depth reading of the literature, it is found that among the influencing factors of UIC, the influencing factors are classified into three categories: Individual characteristics (including gender, age, professional title, academic research ability, UIC experience), institutional characteristics (support of 
university research institutions, academic quality of university research institutions, atmosphere of university research institutions, industry university research cooperation orientation) and Organisational context (including the classification of subjects in different national systems, national policy environment).

Among the influences brought by UIC, the effects are: the impact on the academic research of scientific researchers (quantity and quality of academic publications, research direction), the impact on the commercialized output and the impact on the teaching output of researchers. On the basis of previous studies, referring to Perkmann's research framework (Perkmann, Tartari, \& Mckelvey et al., 2013), the research framework of all literature on the interaction of production, learning and research at the individual level is summarized, as shown in Figure 4. Existing research focuses on the influence of personal characteristics, institutional characteristics and Organisational context on the participation of researchers in UIC, as well as the impact of UIC on the performance of researchers. Therefore, this paper will elaborate on the current research situation from three aspects: the related concepts, the motivation, the influencing factors and the influence of the UIC.

\section{The Influence Factors of UIC}

Boardman and Ponomariov suggest that the differences in individual researchers directly affect their participation in UIC (Boardman \& Ponomariov, 2009). Perkmann and others have divided the influence factors of researchers' coopera-

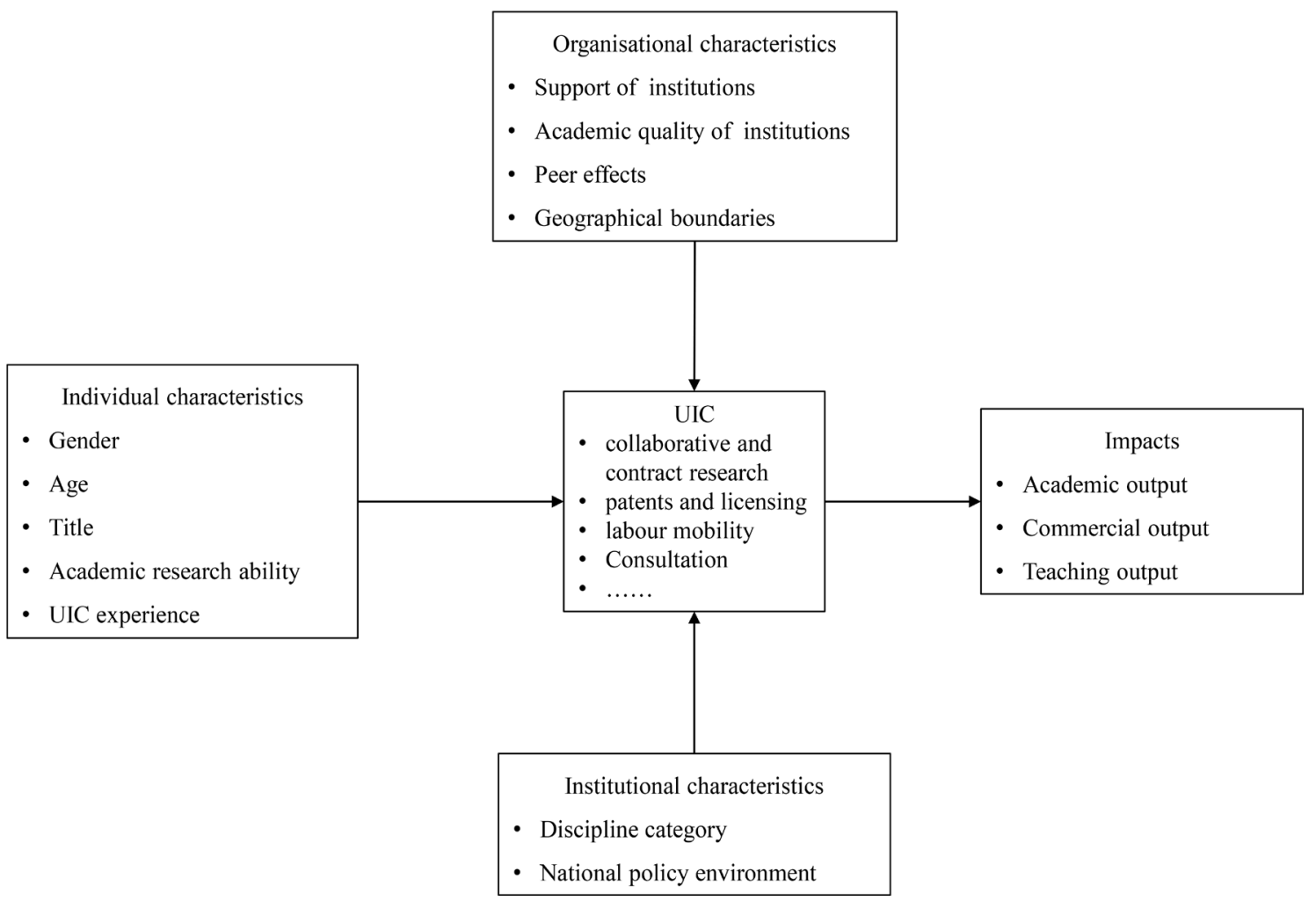

Figure 4. Framework for Research in UIC. 
tion in production, learning and research into three categories, namely, individual factors, organizational factors, and institutional factors (Perkmann, Tartari, \& Mckelvey et al., 2013). D’Este's comparative study of three factors found that the influence of individual factors on the participation of researchers in UIC was most obvious compared with organizational and institutional factors (D'Este \& Patel, 2007). From the perspective of personal factors, the study is generally concerned about the demographic characteristics of scholars such as age, gender (Azagra-Caro, 2007; Haeussler \& Colyvas, 2011; Perkmann, King, \& Pavelin, 2011; Giuliani, Morrison, \& Pietrobelli et al., 2010); Professional status such as title (D'Este \& Patel, 2007); Academic competence such as academic paper productivity experience in UIC (D'Este \& Patel, 2007), Geographical distance and regional boundaries (Chen, Patton, \& Kenney, 2016; Thursby \& Thursby, 2011). From the point of view of organizational factors, the academic quality, academic atmosphere and peer effect and research institutions are the main factors affecting individual participation in UIC. From the institutional factors, the government's policy support, discipline categories and other factors are the main factors.

\subsection{Individual Characteristics}

From the perspective of individual factors, the first view of the effect of age on participation in UIC is basically the same, when the evaluation of the academic title, the study found that the older scholars are more inclined to participate in the UIC (Boardman \& Ponomariov, 2009), D’Este \& Patel and Mário to investigate whether the age of the scholars to participate in the interaction of production and research curve effect, found that age on whether scholars participate in the UIC is an inverted U-shaped curve (D'Este \& Patel, 2007; Franco, Haase, \& Fernandes, 2014). For gender studies, existing studies generally agree that male scholars are more inclined to interact with industry, but Giuliani and others have looked at researchers working with the wine industry in Chile, Italy and South Africa and found that female scholars are more involved with businesses, but the study involves only a single wine industry (Giuliani, Morrison, \& Pietrobelli et al., 2010).

Compared with the inconsistency of age and gender research conclusions, the influence of personal titles on participation of researchers in UIC and research is the same in academic circles. Titles reflect the quality of research, academic reputation, and position level of researchers. Researchers with senior titles have higher research quality and competence, are able to mobilize more resources, and are competent for the work of industry, science and research, and existing studies have shown that higher-level researchers are more inclined to participate in the interaction of industry, science and research (D'Este \& Patel, 2007; Giuliani, Morrison, \& Pietrobelli et al., 2010). Higher titles have a larger network of social capital, which in turn enables them to find potential industry partners, and this network effect is enhanced by their daily interaction with industry 
partners. The previous interactive experience of UIC has accumulated social capital, and the interactive experience of academic enterprises will prompt academic researchers to change the stereotype that UIC will negatively affect academic research. The findings of the study all support the tendency of researchers with experience in production, research and development to participate in the interaction of production and research (D’Este \& Patel, 2007; Giuliani, Morrison, \& Pietrobelli et al., 2010).

\subsection{Organizational Factors}

The study points out that the academic quality, organizational structure, age and peer effect of academic research institutions will affect the interaction of scientific researchers' participation in UIC, the most significant organizational-level determinants are the academic quality of the research institutions or departments where the scholars are located, and the overall impact of academic quality at the organizational level on the participation of scholars in the UIC activities is negative (D’Este \& Patel, 2007; Boardman \& Ponomariov, 2009). Perkmann explains that less government research funding is available to research institutions with poor academic quality, prompting organizations to see the UIC as a means of obtaining research funding (Perkmann, Tartari, \& Mckelvey et al., 2013; Chen, Patton, \& Kenney, 2016). If there are entities in universities that support the UIC (such as TTOS), they will also increase the propensity of researchers to participate in the UIC (Chen, Patton, \& Kenney, 2016). A small number of scholars are concerned about the relationship between organizational age and UIC, a study, such as Azagra-Caroe and other studies have found that organizational age also negatively affects the participation of researchers in the UIC (Azagra-Caro, 2007). Early scholars Louis pointed out that the influence of individual characteristics on participation in the UIC was strongly regulated by the group level norms. This view is also supported by research by Haeussler and Colyvas, which suggests that researchers are more likely to advise businesses if their colleagues value patents and awards, and the opposite is true if their colleagues value traditional academic values (Haeussler \& Colyvas, 2011).

\subsection{Institutional Factors}

From the institutional factors, scholars on the influence of scholars on the field of research, and early research found that the subject areas are related to the participation of researchers in UIC. In the study, Bekkers and Freitas and Martinelli found that scholars in applied research fields were more likely to participate in the interaction of industry, such as engineering (Bekkers \& Freitas, 2008; Martinelli, Meyer, \& Von Tunzelmann, 2008), with different degrees of UIC between researchers in different disciplines and fields of research. Disciplines influence the choice of channels for researchers to interact with their research and development. The study by Bekkers and Freitas found that the most important interactive channels in the field of bioengineering and chemical engineering are pa- 
tent applications, patent licensing and contract research, and patent licensing channels are the most important in the field of materials science, but patent behavior is not commonly used in the field of computer science, and in the field of social science, the most common forms of interaction between researchers and enterprises in research and research institutions are the movement of people (Bekkers \& Freitas, 2008).

\section{The Impact of UIC}

\subsection{Impact on the Output of Academic Papers}

The influence of participating in the interaction of production, learning and research on the academic research and the output of scientific has always been the focus of academic attention. Some studies show that the UIC is a channel of two-way knowledge flow between academia and industry. On the one hand, the scientific knowledge of scientific researchers can promote technological innovation in enterprises, on the other hand, the practical experience and problems of enterprises can bring new ideas and directions to scientific research, thus improving the performance of academic output (Chen \& Zhu, 2014). Furthermore, cooperation with enterprises can also enable researchers to obtain additional financial support and complementary resources such as experimental equipment (Diao, Zhu, \& Xu, 2011), and improve the quantity and quality of the results of the paper (Hottenrott \& Lawson, 2017).

However, another part of the view that participation in the UIC will reduce the input of scientific research, will distract researchers' time and energy, change the direction of research, limit the academic freedom of researchers, there is a "crowding out effect", the academic output of scholars is not conducive (Thursby \& Thursby, 2011), scholars first worried that the work of research and research cooperation will distract scholars' energy (Thursby \& Thursby, 2007). Fbrizio \& Di Minin and Lowe \& Gonzalez believed that the participation of researchers in patent and commercial activities will distract researchers from the resources and attention of scientific research (Fabrizio \& Di Minin, 2008; Lowe \& Claudia, 2007), as the time and research resources of researchers are limited, and the participation of the market will transform the research of researchers from basic to application (Forida \& Cohen, 1999).

\subsection{Impact on the Output of Patent}

Interaction with enterprises enables researchers to better understand market demands and technological opportunities, and to enhance their propensity and capabilities for innovation and development (Bikard, Vakili, \& Teodoridis, 2019). UIC enables researchers to gain a deeper understanding of the technical needs and practical issues of enterprises in the enterprise site, and to develop targeted solutions and technological achievements. Enterprises will also be fully supported by funding, personnel, equipment, instruments, materials and data, which will contribute to valuable collaborative and innovative output. However, 
many valuable technological achievements (e.g. process innovation) are difficult to protect through patents. After the patent application, competitors can obtain publicly released patented technology documents to imitate or develop evasive technology to bypass patent barriers, resulting in a loss of business earnings. In this case, enterprises tend not to patent, choose to use technology secret protection cooperative innovation results. In addition, close cooperation between researchers and enterprise technicians can enable both sides to better understand each other's advantages, enhance the division of cooperation, so that researchers more focused on providing theoretical methods, scientific knowledge and basic research and other innovative inputs, and more practical and operational experience of enterprise technical personnel to lead the technical and patent development work (Bikard, Vakili, \& Teodoridis, 2019). In this way, the two parties will be more inclined to choose the "back door" path that excludes academic institutions from patent ownership (Goel \& Goktepe-Hulten, 2018), or "informal” paths such as individual consulting agreements, to transfer innovations developed by enterprises (and even some by researchers) (Halilem, Amara, \& Olmos-Penuela et al., 2017).

\section{Conclusion}

\subsection{Summary of the Current Situation of Research}

The following conclusions are found through a systematic review of the literature satouts of research related to the cooperation between industry, science and research.

1) This study finds that the current research direction on this topic is divided into two aspects: first, the impact factors of researchers' participation in UIC; Second, the impact of UIC on the performance of scientific researchers. Most of these literatures pay attention to the research of the influence factors of industrial, academic and research cooperation, only a few literature research from the perspective of the impact of UIC on scientific researchers, and some conclusions are more controversial: on the one hand, the UIC will harm the academic and innovative performance of scientific researchers, on the other hand, The UIC will promote the academic and innovative performance of scientific researchers.

2) Scholars generally examine the forms of cooperation in production, research and research, such as joint patent applications and contract research, and because of the limitation of data, no research has been found on the relationship between the University-Industry Mobility and the performance of scholars. Compared with the interactive forms of joint patent application, cooperative research, consulting and so on, the University-Industry Mobility has special purposes, organizational mechanisms and procedures, so that researchers cross the boundary of production and knowledge, organizational boundaries and geographical areas, and go deep into the first line of enterprise technology research and development site, which will bring about differential impact.

3) In previous studies on the interaction between industry and research and 


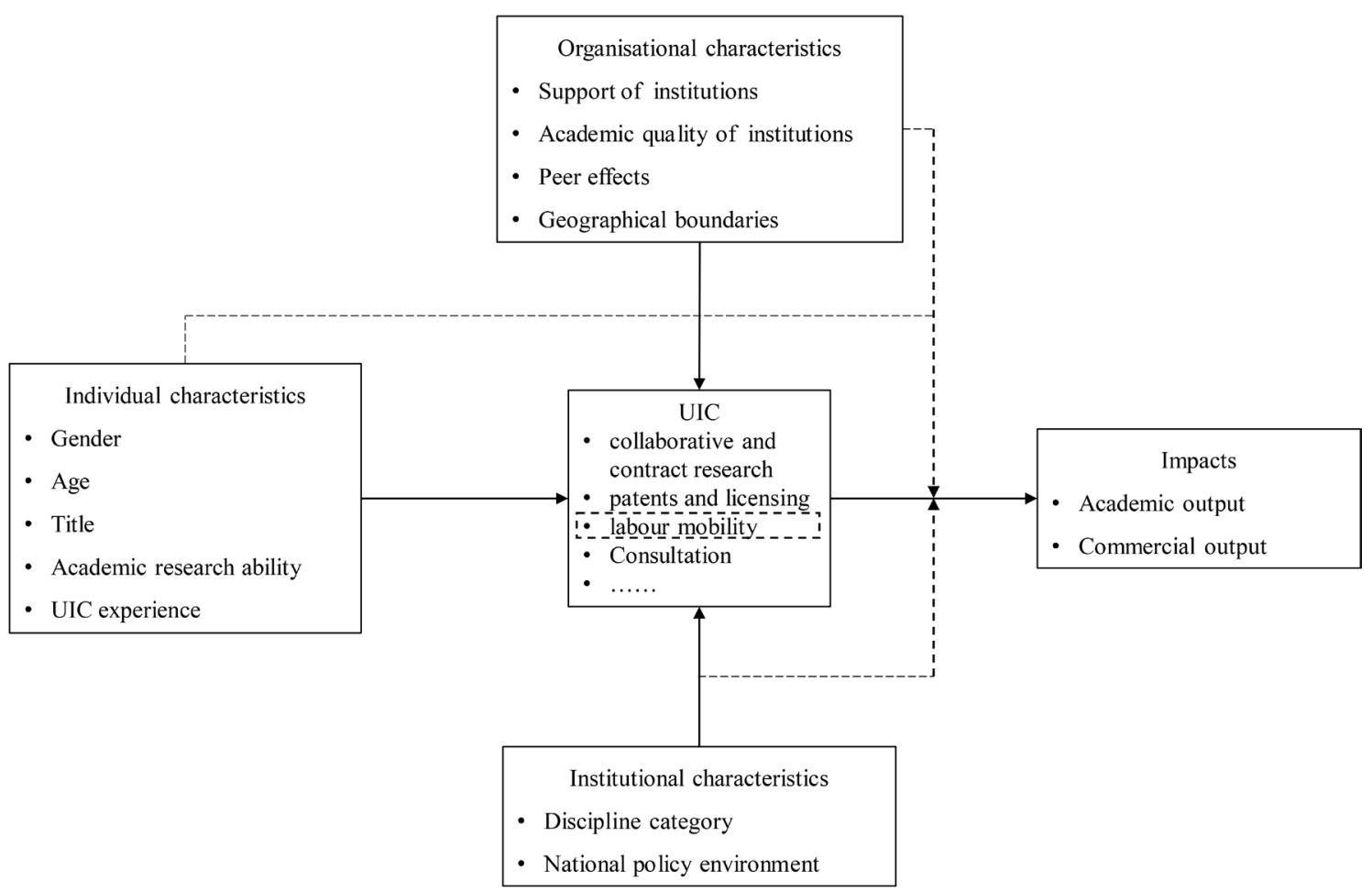

Figure 5. Research conclusions and prospects.

the academic and innovative performance of researchers, different types of papers (domestic and international papers), different types of patents (invention patents and utility model patents) may have different potential academic values, application value and impact on the scope of communication, so that participating in the flow of academic and enterprise personnel will have a differentiated impact on the publication of different types of papers and patent applications. Secondly, the existing literature focuses on the analysis of different personal characteristics, organizational characteristics, institutional characteristics of individual participation in the decision-making, the degree of UIC. Few studies examine the adjustment effect of individual characteristics, organizational characteristics and system characteristics on the relationship between the interaction of production, research and research and the performance of scientific research personnel.

\subsection{Research Prospects}

Combined with the previous research, the following research prospect Figure 5, in which the real line is the subject of general concern in the academic circles, the dotted line represents the subject that the academic circle has not paid attention to or has little research. Therefore, the current research can also be studied in the following areas: 1) Pay attention to how different individual characteristics, institutional characteristics and institutional characteristics of the flow of personnel in academic enterprises affect the degree of UIC; 2) Pay attention to the impact of UIC of university-industry mobility on the academic and innova- 
tive performance of researchers; 3) The differences in the impact of different individual characteristics, organizational characteristics and institutional characteristics.

\section{Conflicts of Interest}

The author declares no conflicts of interest regarding the publication of this paper.

\section{References}

Azagra-Caro, J. M. (2007). What Type of Faculty Member Interacts with What Type of Firm? Some Reasons for the Delocalisation of University-Industry Interaction. Technovation, 27, 704-715. https://doi.org/10.1016/j.technovation.2007.05.003

Bekkers, R., \& Freitas, I. M. B. (2008). Analysing Knowledge Transfer Channels between Universities and Industry: To What Degree Do Sectors Also Matter? Research Policy, 37, 1837-1853. https://doi.org/10.1016/j.respol.2008.07.007

Bikard, M., Vakili, K., \& Teodoridis, F. (2019). When Collaboration Bridges Institutions: The Impact of University-Industry Collaboration on Academic Productivity. Organization Science, 30, 426-445. https://doi.org/10.1287/orsc.2018.1235

Boardman, P. C., \& Ponomariov, B. L. (2009). University Researchers Working with Private Companies. Technovation, 29, 142-153.

https://doi.org/10.1016/j.technovation.2008.03.008

Chen, A. H., Patton, D., \& Kenney, M. (2016). University Technology Transfer in China: A Literature Review and Taxonomy. Journal of Technology Transfer, 41, 891-929. https://doi.org/10.1007/s10961-016-9487-2

Chen, C. H., \& Zhu, G. L. (2014). The Impact of Scholars' Social Capital in University-Industry Link on Scholars' Performance. Science of Science and Management of S. \& T., 35, 85-93.

D’Este, P., \& Patel, P. (2007). University-Industry Linkages in the UK: What Are the Factors Underlying the Variety of Interactions with Industry? Research Policy, 36, 1295-1313. https://doi.org/10.1016/j.respol.2007.05.002

Diao, L. L., Zhu, G. L., \& Xu, Z. (2011). Review, Prospect and Enlightenment of the Research on University-Industry Cooperation. Foreign Economies and Management, 33, 48-57.

Fabrizio, K. R., \& Di Minin, A. (2008). Commercializing the Laboratory: Faculty Patenting and the Open Science Environment. Research Policy, 37, 914-931.

https://doi.org/10.1016/j.respol.2008.01.010

Forida, R., \& Cohen, W. (1999). Engine or Infrastructure? The University Role in Economic Development. Industrializing Knowledge: University-Industry Linkages in Japan and the United States. Cambridge, MA: MIT Press.

Franco, M., Haase, H., \& Fernandes, A. (2014). The Influence of Academic Staff's Personal and Professional Characteristics on the Decision to Cooperate with Industry. European Journal of International Management, 8, 293-309. https://doi.org/10.1504/EJIM.2014.060770

Giuliani, E., Morrison, A., Pietrobelli, C. et al. (2010). Who Are the Researchers that Are Collaborating with Industry? An Analysis of the Wine Sectors in Chile, South Africa and Italy. Research Policy, 39, 748-761. https://doi.org/10.1016/j.respol.2010.03.007

Goel, R. K., \& Goktepe-Hulten, D. (2018). What Drives Academic Patentees to Bypass TTOs? Evidence from a Large Public Research Organisation. Journal of Technology 
Transfer, 43, 240-258. https://doi.org/10.1007/s10961-017-9595-7

Haeussler, C., \& Colyvas, J. A. (2011). Breaking the Ivory Tower: Academic Entrepreneurship in the Life Sciences in UK and Germany. Research Policy, 40, 41-54. https://doi.org/10.1016/j.respol.2010.09.012

Halilem, N., Amara, N., Olmos-Penuela, J. et al. (2017). “To Own, or Not to Own?” A Multilevel Analysis of Intellectual Property Right Policies' on Academic Entrepreneurship. Research Policy, 46, 1479-1489. https://doi.org/10.1016/j.respol.2017.07.002

Hottenrott, H., \& Lawson, C. (2017) Fishing for Complementarities: Research Grants and Research Productivity. International Journal of Industrial Organization, 51, 1-38. https://doi.org/10.1016/j.ijindorg.2016.12.004

Lowe R. A., \& Claudia, G. B. (2007). Faculty Entrepreneurs and Research Productivity. Journal of Technology Transfer, 32, 173-194. https://doi.org/10.1007/s10961-006-9014-y

Martinelli, A., Meyer, M., \& Von Tunzelmann, N. (2008). Becoming an Entrepreneurial University? A Case Study of Knowledge Exchange Relationships and Faculty Attitudes in a Medium-Sized, Research-Oriented University. Journal of Technology Transfer, 33, 259-283. https://doi.org/10.1007/s10961-007-9031-5

Perkmann, M., King, Z., \& Pavelin, S. (2011). Engaging Excellence? Effects of Faculty Quality on University Engagement with Industry. Research Policy, 40, 539-552. https://doi.org/10.1016/j.respol.2011.01.007

Perkmann, M., Tartari, V., Mckelvey, M. et al. (2013). Academic Engagement and Commercialisation: A Review of the Literature on University-Industry Relations. Research Policy, 42, 423-442. https://doi.org/10.1016/j.respol.2012.09.007

Thursby, J. G., \& Thursby, M. C. (2007). University Licensing. Oxford Review of Economic Policy, 23, 620-639. https://doi.org/10.1093/oxrep/grm031

Thursby, J. G., \& Thursby, M. C. (2011). Faculty Participation in Licensing: Implications for Research. Research Policy, 40, 20-29. https://doi.org/10.1016/j.respol.2010.09.014 